\title{
ABRAHAM LICOLN DALAM KARYA MARK RYDEN
}

\author{
Larasati Sekar Arum \\ Institut Teknologi Bandung \\ larasatisekar@gmail.com
}

\begin{abstract}
ABSTRAK
Seni surealisme adalah sebuah aliran seni yang menunjukkan kebebasan berkreativitas yang melampui batas logika. Pada masa setelah Perang Dunia I, seni surealisme lebih dikenal untuk mengkritik pemeritahan terhadap kehancuran lingkungan pasca perang. Namun, saat ini seni surealisme lebih dikenal dengan untuk mengekspresikan diri yang lebih bebas melampaui batasan-batasan seperti rasionalitas, kebiasaan, dan pola. Seperti Mark Ryden seorang seniman surealis asal amerika yang mengekspresikan diri dengan menggunakan objek seperti mainan tua, organ tubuh, kerangka, dan lain-lain. Dalam karyanya, Mark sering sekali menggunakan Abraham Lincoln, entah itu untuk pesan tersirat atau hanya karena keinginannya semata. Untuk itu, akan dilakukan pengamatan mengapa Abraham Lincoln sering sekali muncul pada lukisan Mark Ryden. Pengumpulan data akan dilakukan melalui pengamatan dokumen.
\end{abstract}

Kata kunci: surealisme, seniman, Mark Ryden, Presiden, Abraham Lincoln

\section{Pendahuluan}

Seni surealisme adalah sebuah aliran seni yang menunjukkan kebebasan berkreatifitas yang melampaui batas logika. Selain itu surealisme juga didefinisikan sebagai gerakan budaya yang mempunyai unsur kejutan sebagai ungkapan filosofis. Surealisme bersifat tidak beraturan. Warna yang digunakan dalam aliran surealisme cenderung melompat-lompat antara warna yang terkesan sejuka dan hangat. Objek- objek yang digunakan biasanya meliputi benda yang sebenarnya tidak saling berhubungan satu sama lain, tetapi jika diamati lebih lanjut benda-benda tersebut memliki makna yang saling berkaitan satu sama lain.

Surealisme, mulanya digunakan untuk menuangkan kekesalan para kaum Dada terhadap kehancuran yang diakibatkan oleh Perang Dunia 1. Namun, saat ini surealisme lebih cenderung digunakan untuk memperbaharui pengalaman manusia yang meliputi aspek individu, budaya, sosial, dan politik dengan membebaskan manusia dari apa yang 
mereka lihat sebagai rasiaonalitas palsu, kebiasaan dan pola yang terbatas. Kebebasan tersebut dimafaatkan oleh salah satu seniman pop surealis asal amerika. Objek yang biasanya digambarkan oleh Mark berupa mainan tua, organ tubuh, kerangka manusia, dan hewan.

Namun, ada sesuatu yang menarik pada beberapa lukisan Mark. Beberapa lukisan Mark seringkali memunculkan sesosok tokoh yang terbilang sangat fenomenal, yaitu Abraham Lincoln. Pada beberapa karyanya, Mark sering menyelipkan tokoh Abraham Lincoln. Telah ditemukan sebanyak sekitar 19 Lincoln pada 19 karya. Dalam lukisannya, Mark cenderung lebih banyak menyelipkan Abraham Lincoln dengan ukuran yang cukup kecil sehingga apabila tidak diperhatikan dengan jeli maka tokoh tersebut tidak akan terlihat.

Melalui pengumpulan data yang dilakukan dengan studi dokumen, dapat diketahui “Mengapa Abraham Lincoln sering sekali muncul pada beberapa karya Mark Ryden?” dan “Apakah ada kaitannya dengan peristiwa pada saat itu sehingga Mark Ryden memasukannya dalam karyanya?"

\section{Sampling dan Metode}

Pengambilan data dilakukakan dengan cara studi dokumen yang diambil dari biografi dan dokumen hasil wawancara. Setelah data telah dikumpulkan, seluruh karya akan dikelompokkan berdasarkan tahun pembuatnnya. Hal ini dilakukan untuk mempermudah dalam pencarian objek pengamatan.

Metode studi dokumen terbagi menjadi dua yaitu dokumen primer dan dokumen sekunder. Dokumen sekunder merupakan dokumen yang ditulis kembali oleh orang yang tidak langsung mengalami peristiwa, sedangkan dokumen primer merupakan dokumen yang dituis langsung oleh orang yang mengalami peristiwa tersebut. Dalam pengamatan ini, dokumen yang akan sering digunakan adalah dokumen sekunder. 


\section{Pembahasan}

Berikut adalah daftar karya Mark berikut dengan judul lukisan serta tahun pembuatannya.

\begin{tabular}{|c|c|c|}
\hline Lukisan & $\begin{array}{c}\text { Judul } \\
\text { Lukisan }\end{array}$ & $\begin{array}{c}\text { Tahun } \\
\text { Pembuatan }\end{array}$ \\
\hline & The Birth & 1994 \\
\hline Gumber(markryden.com/paintings/two/index.html) & & \\
\hline Gambar 1.1 & & \\
\hline
\end{tabular}




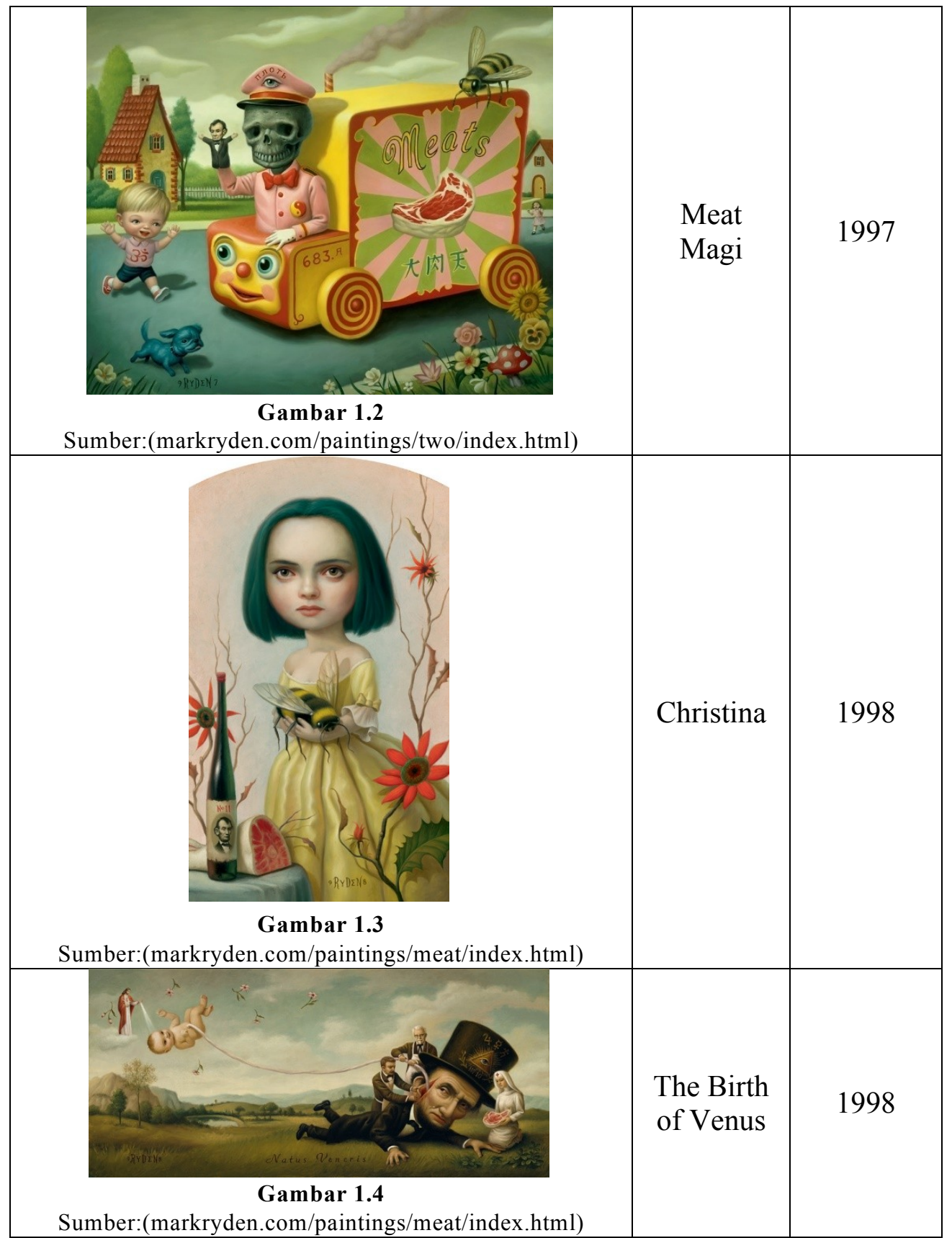




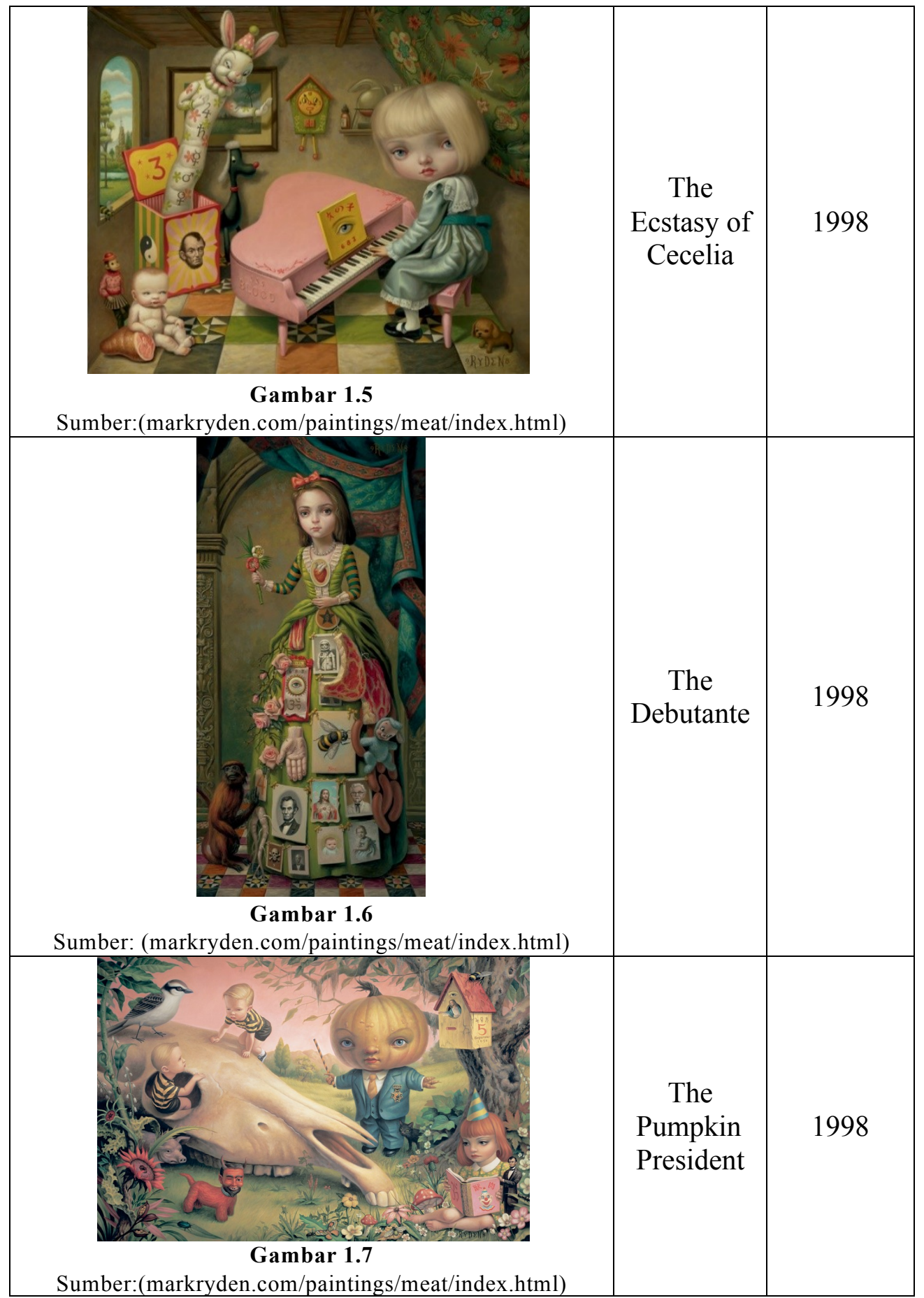




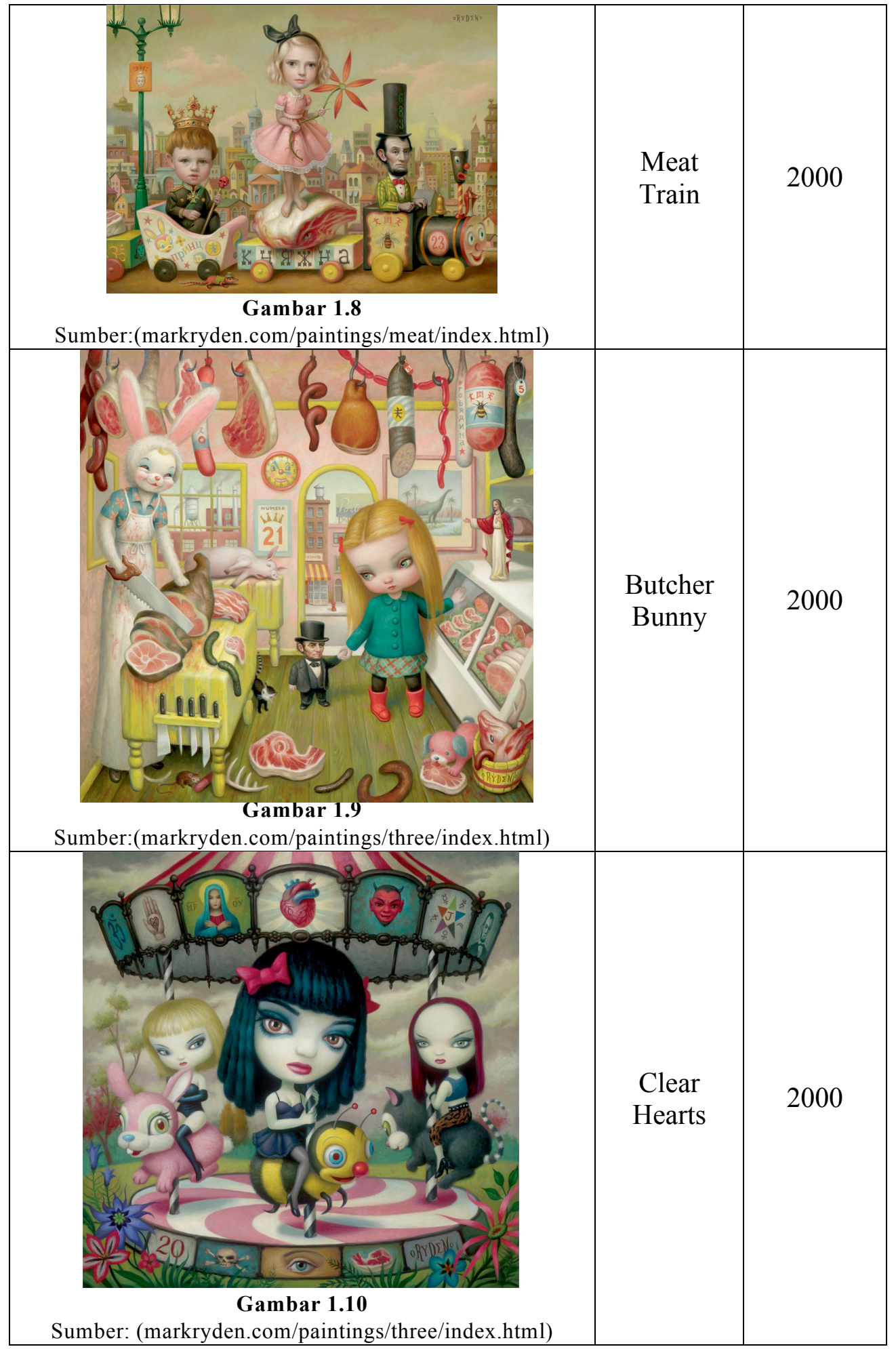




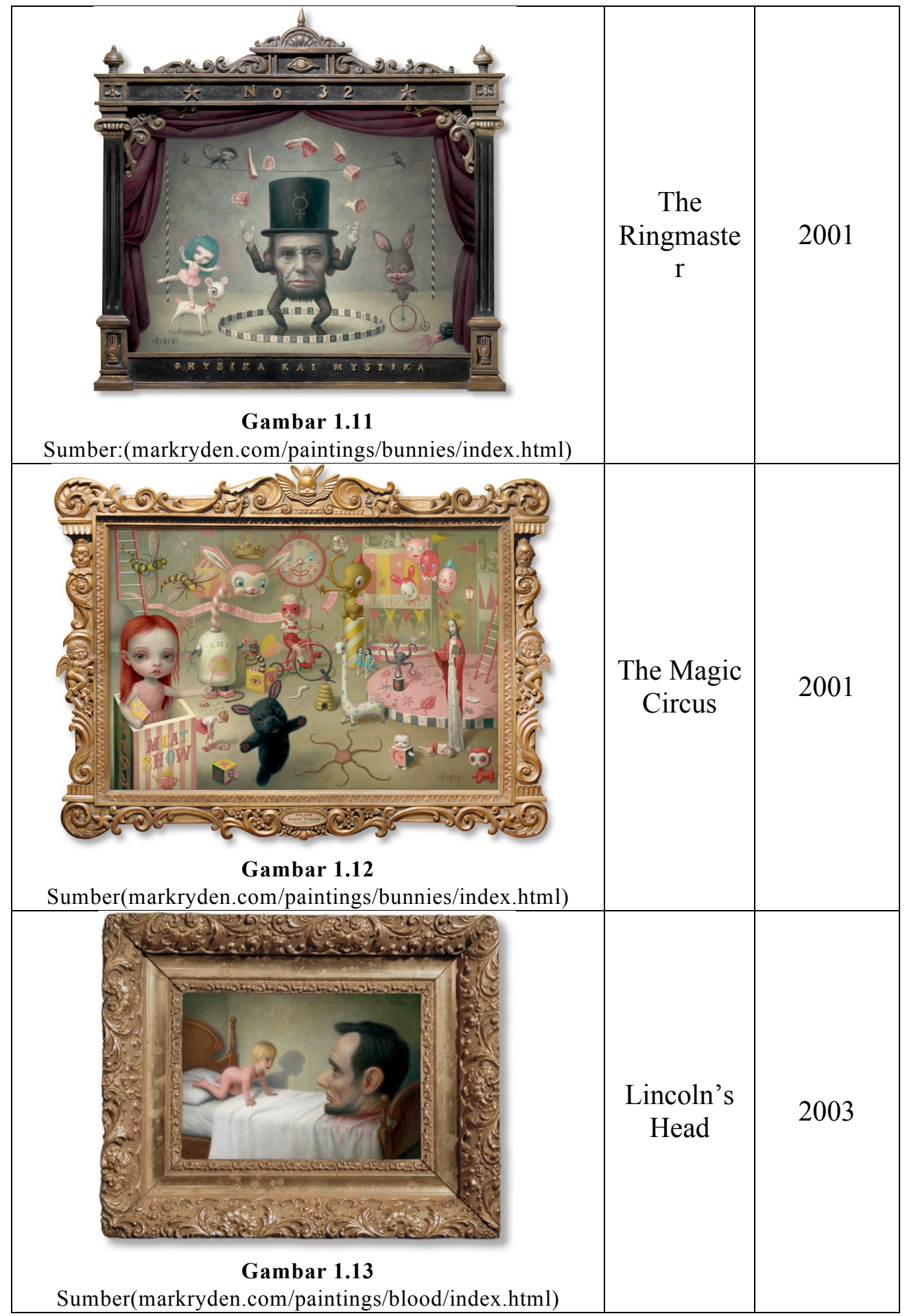




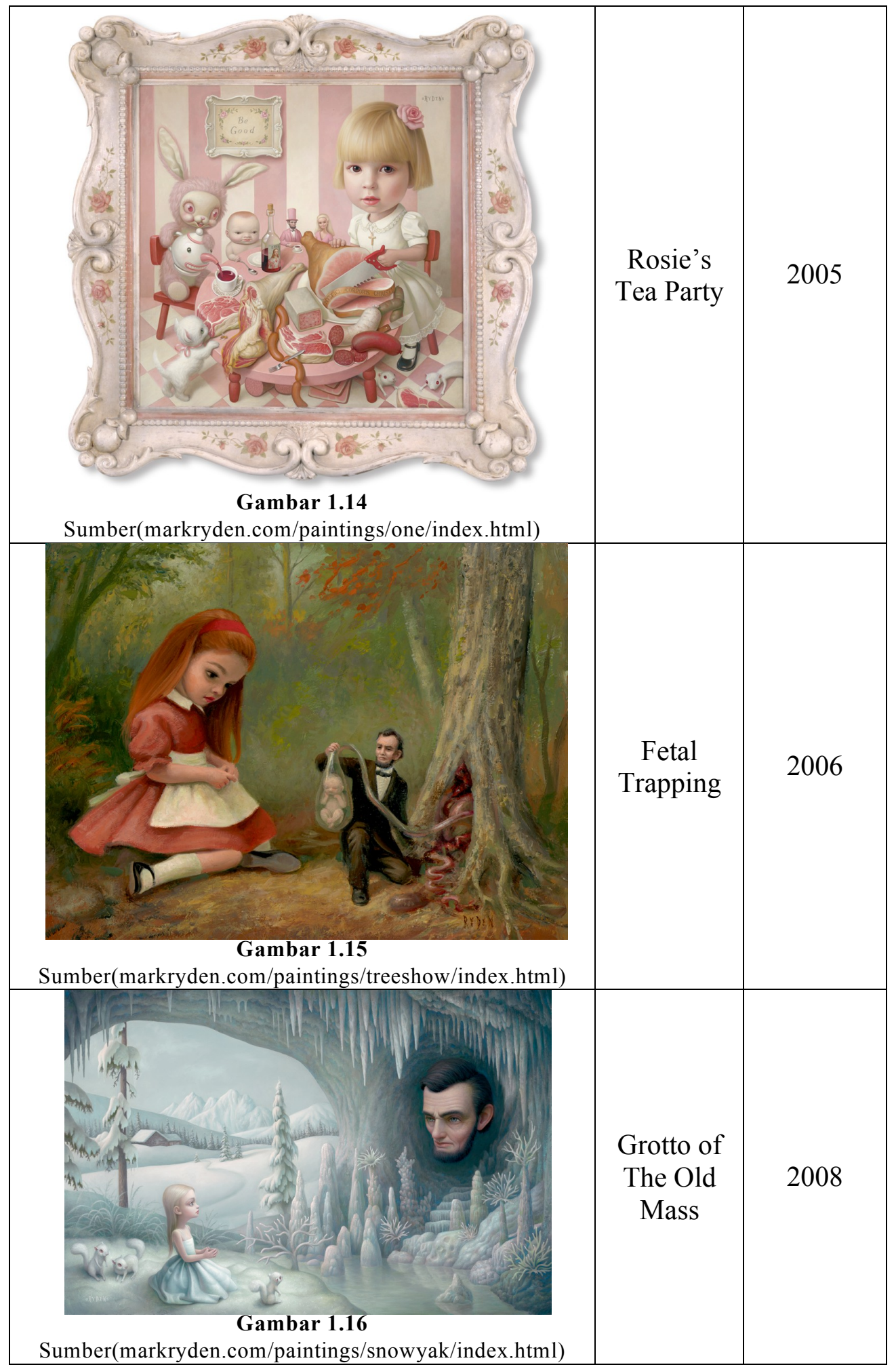




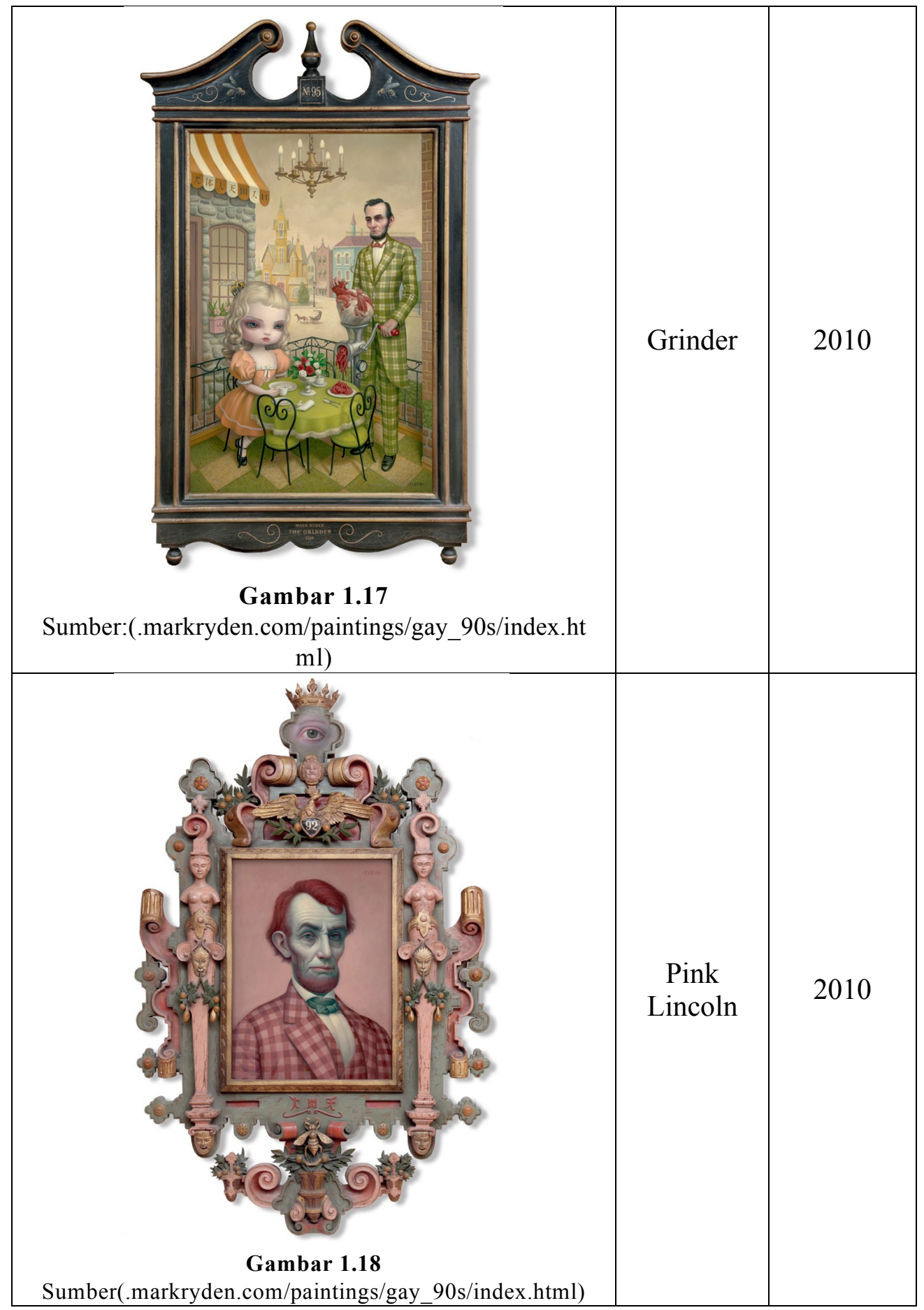




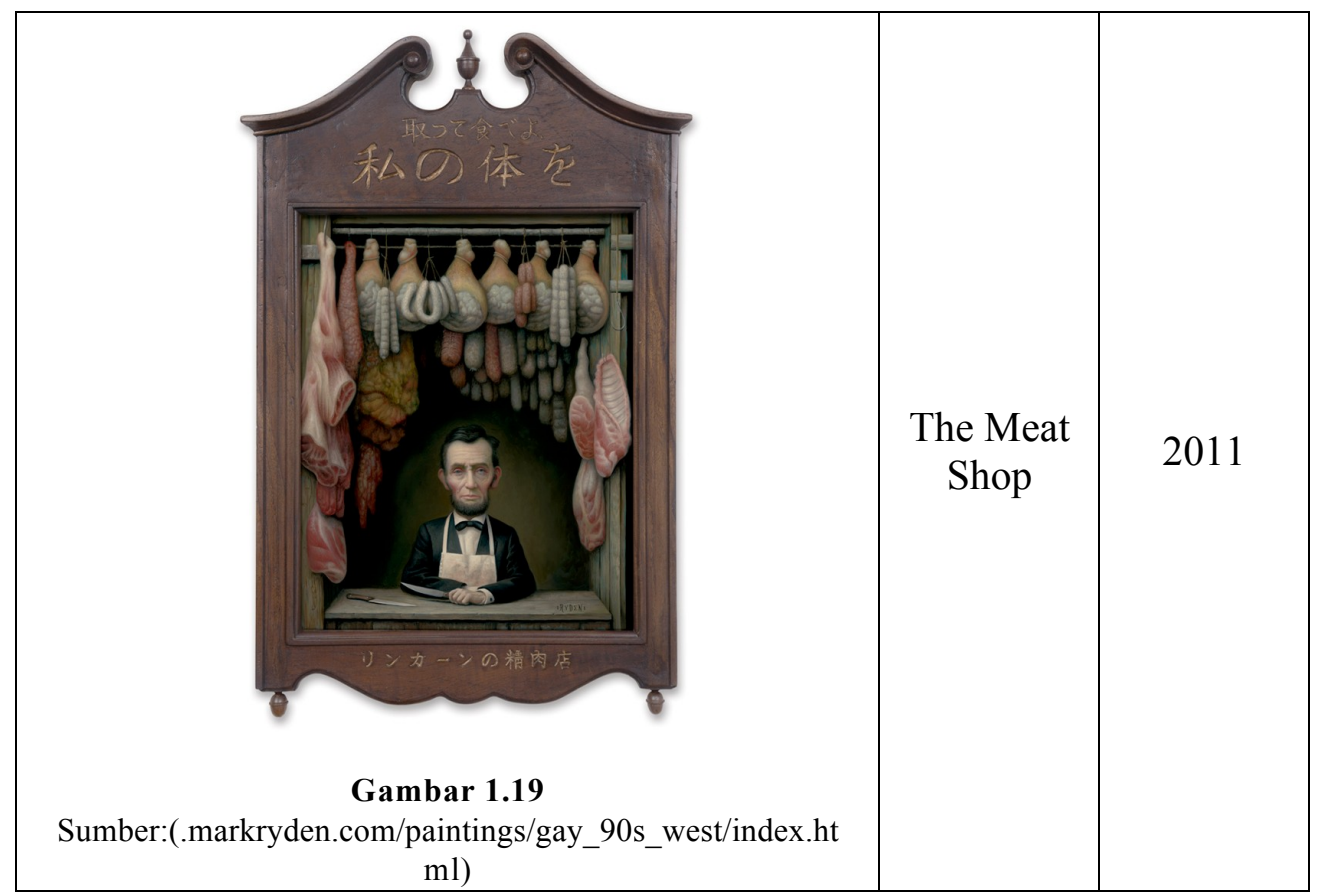

Data-data di atas merupakan seluruh karya Mark Ryden yang terdapat sosok Abraham Lincoln. Data-data ini juga sudah diurutkan berdasarkan waktunya. Hal ini ditujukan untuk meneliti apakah dalam kurun waktu tersebut terjadi peristiwa yang menyangkut Abraham Lincoln atau penggunaan Abraham Lincoln hanya sebagai pemanis dari karya seni tersebut. Setelah dipelajari lebih lanjut, rupanya lukisan tersbut tidak ada sangkut pautnya terhadap peristiwa yang pernah dialami oleh Lincoln.

\section{Hasil}

Lincoln dalam lukisan karya Mark hanya digunakan sebagai pemanis karena wajahnya yang sangat iconic. Mark menggunakan Abraham Lincoln sebagai modelnya karena kekakugamannya terhadap Lincoln dan juga wajah Lincoln sangatlah unik dan yang paling sering terbayang. Hal tersebut semakin jelas ketika Mark memaparkan pada wawancara di Hollywoodreporter.com (20004) bahwa:

"I obviously get asked that question a lot, and I don't have a real good answer for it. The best answer is: because it gives you those questions yourself of, "What the hell is Abraham Lincoln doing?" And I like that. I resist, actually, putting in Abraham Lincoln, but I find myself time and time again just not being able to resist it. If you 
Arkhais, Vol. 08 No. 1 Januari-Juni 2017

want to have a conversation about Abraham Lincoln aside from why I put him in my paintings, I could talk what I think about Abraham Lincoln. He became like a saint to the country more than any other figure had. There's something about the power of his face, because he was one of the first famous people to be heavily photographed ever, and he has such a strange face. It just sticks with you."

Apa yang dikatakan Mark tentang Lincoln sangatlah benar. Selain wajahnya yang terkenang, seluruh jasa-jasa yang ia lakukan selama hidup pun akan selalu dikenang oleh masyarakat. Abraham Lincoln adalah seorang Presiden ke-16 Amerika Serikat. Pada masanya, Lincoln terkenal sebagai sosok yang sangat dibanggakan. Hal itu disebabkan oleh beberapa faktor, yaitu pada masa itu Lincoln adalah seorang pemimpin yang memperjuangkan bangsanya agar dapat keluar dari perang saudara, kemudian Lincoln merupakan pemimpin yang sangat memertahankan persatuan bangsanya dan saat Abraham Lincoln diangkat menjadi presiden, ia melakukan tindakan pembebasan perbudakan. Pada tanggal 15 April 1865, ia menghembuskan nafas terakhirnya karena peluru yang ditembakkan ke arah kepala Licoln oleh John Wikes Booth yang merupakan salah satu fanatik dari kelompok konfederasi.

\section{Simpulan}

Dari data-data di atas dapat ditarik kesimpulan bahwa Mark tidak menggunakan Lincoln sebagai tokoh yang digunakan untuk menganalogikan sesuatu. Mark menggunakan Lincoln karena wajahnya yang sangat iconic. Jika diamati, kemungkinan penggunanan Abraham Lincoln ditujukan agar oarng-orang tertarik untuk melihat karyanya dan merasa penasaran dengan makna apa yang terkandung dibalik penggunaan sosok Abraham Lincoln tersebut. Namun, penggunaan tokoh Abraham Lincoln tersebut tidak memiliki maksud apa-apa. Mark Ryden sendiri bingung mengapa sosok Abraham Lincoln terus terbayang di kepalanya. Hal tersebutlah yang membuat beberapa karya Mark Ryden terdapat seorang Abraham Lincoln.

\section{Daftar Pustaka}

E. supriana, Caca (2016, Januari 29). caca-e- supriana.blogspot.co.id. diakses pada 28 April 2017, pukul 0.13 dari caca- e-supriana.blogspot.co.id: http://cacae- supriana.blogspot.co.id/2016/01/surealisme.html

Al-Gharuty, F (2009, Februari 2).adzelgar.wordpress.com diakses pada 26 April 2017 pukul 21.00 dari adzelgar.wordpress.com: 
Arkhais, Vol. 08 No. 1 Januari-Juni 2017

https://adzelgar.wordpress.com/2009/02/02/studi-dokumendalampenelitian-kualitatif/

Vityana, Iva (2015, Juli 3). www.biografipedia.com. diakses pada 27 April 2017, pukul 23.57 dari www.biografipedia.com: http://www.biografipedia.com/2015/07/biografi-abraham-lincoln-presidenke-16-amerika-serikat.html

Williams. Maxwell (2014, Agustus 5). www.hollywoodreporter.com. diakses pada 27 April, 2017, pukul 0.24 dari www.hollywoodreporter.com: http://www.hollywoodreporter.com/news/artist-mark-ryden-talks-new702365

Revolta, Rezza (2013, April 15). www.kompasiana.com diakses pada 28 April 2017, pukul 5.04 dari www.kompasiana.com http://www.kompasiana.com/rezzrevolta/mengenang-terbunuhnyaabraham-lincoln-15-april_551f7b48a333113a2db66f0 